\title{
The influence of theoretical concepts on the practice of assessing the quality of knowledge in the 1920-1930s
}

\author{
Irina Vladimirovna Vladykina $^{1}$, Natalia Gennadievna Dyukina, Natalia Vladimirovna \\ Leontyeva, Natalia Leonidovna Yugova, and Lyubov Leonidovna Kutyavina \\ Glazov State Pedagogical Institute named after V.G. Korolenko, Department of Mathematics and \\ Informatics, Glazov, Russia
}

\begin{abstract}
A significant component of higher education didactics is the assessment of the quality of students' knowledge, which allows determining the effectiveness of the work of the participants in the educational process. Assessment of the quality of students' knowledge, considered at various levels, is of interest not only from the standpoint of modern didactics, but also in the historical aspect. Theoretical representations of teachers of the 1920-1930s on the assessment had an impact on the practice of organizing the work of universities. The selected chronological framework (1917-1939) is characterized by active transformations in the educational sphere, significant development of pedagogical thought. The study aims to substantiate the development trend of the practice of assessing the quality of students' knowledge on the basis of theoretical ideas of teachers of the period under review. The work employs a general theoretical modeling method aimed at building basic models for assessing the quality of students' knowledge. In addition, special historical and pedagogical methods were used: historical-structural, historical-comparative and constructive-genetic ones. The employment of these methods makes it possible to describe the main structural components of assessment that occur during the studied period of change and identify the main trends. The result of the work was the identification of the main models for assessing the quality of students' knowledge at various stages of the period under consideration: authoritarian control, control based on the "teacher-student" interaction and self-control, as well as control based on the "teacher-student" interaction with the leading role of the teacher. The representations described in the pedagogical literature of that period, which posed the basis for building these models, had a significant impact on the practice of higher education. The novelty of the work consists in identifying the main tendency of strengthening the teacher's priority when assessing the quality of students' knowledge in the "teacher-student" interaction.
\end{abstract}

Keywords: assessment, quality of knowledge, practice of universities

${ }^{1}$ Corresponding author: vladykina07@mail.ru 


\section{Introduction}

The direct organization of the assessment of the quality of students' knowledge in higher education is implemented at various levels. The study of the experience of foreign research on assessment shows that significant attention is paid to the theoretical basis in particular, which has a significant impact on the practice of universities [1,2]. At the same time, not only the current state of the assessment system is of interest, but also the historical view of this problem. Let us study the period of the 1920-1930s, when active reforms were carried out in the education system (1917-1939).

The novelty of the work is due to the fact that, on the basis of the studied theoretical concepts, the following tendency in the development of the practice of assessing the quality of students' knowledge is described: the increasing role of the teacher in assessing the quality of students' knowledge in the process of "teacher-student" interaction.

The study aims to substantiate the development trend of the practice of assessing the quality of students' knowledge on the basis of theoretical ideas of teachers in the 1920-1930s.

Research objectives can be formulated as follows.

1. To highlight the main theoretical models in the views of teachers of the period under review (1917-1939).

2. To substantiate the tendency of the increasing role of the teacher in assessing the quality of students' knowledge in the process of "teacher-student" interaction in the practice of universities on the basis of the selected theoretical concepts.

\section{Methods}

To describe the main theoretical models in the views of teachers, the modeling method was employed, as well as the historical-structural method in order to describe the structural components of the assessment system. Historical-comparative and constructive-genetic methods were used to substantiate the trend of the development of assessment practice.

When choosing the sources, the main attention was paid to the works of the most famous teachers of the 1920-1930s on issues related to assessing the quality of students' knowledge. These works can be divided into two groups: works of a general character dealing with all aspects of assessment and works on specific issues of assessment.

\section{$3 \quad$ Results}

We will take periodization based on its regulatory and legal support as a basis: normative and legal insecurity (1917-1921), experimental search (1922-1931) and normatively defined (1932-1939) [3].

In the context of revolutionary transformations, teachers paid significant attention to the formation of the education system on an innovative basis. As noted by Boguslavsky, in the 1920s representatives of the pedagogical community had opportunities to work under the conditions of the implementation of various pedagogical systems [4]. Most of the teachers (Blonsky, Krupskaya, Shatsky and others) developed conceptual issues of didactics. Particular issues, including those related to assessment, received significantly less attention. At the stage of regulatory insecurity (1917-1921), not a single serious work was written on this issue. A critical analysis of pre-revolutionary views revealed the basic requirements for assessment. In particular, Shatsky proposed a complete rejection of the existing assessment system [5]. According to Kilchevsky, the educational process should be based on the intense activity of the students themselves and their ability to educate themselves [6]. The 
assessment system was an integral part of the educational process, ensuring the reliability of the results obtained. Thus, there was no integral assessment system at the stage of regulatory and legal insecurity (1917-1939).

At the next stage (1922-1931), under the conditions of democratization of management, an active discussion began on how to set up a new school. The result, as pointed out by Pomelov, was the preparation of the foundation for the development of the state in various areas [7]. The teachers approached the creation of the assessment system in different ways, which made it possible to compare, analyze and improve it.

The study of the works of teachers allowed us to identify three main models of the assessment system. In the model of authoritarian control (Blonsky, Mickelson, and others), the main organizer was the teacher, and paramount importance was attached to the definition of objective and reliable learning outcomes $[8,9]$. In the model of control based on the "teacher-student" interaction (Manzhos et al.), it was assumed that control and assessment are to be carried out by the teacher with the active participation of students. Attention was drawn to a meaningful assessment describing the dynamics of students' development. In the model of self-control (Wentzel, Iordansky, et al.), priority was given to the activity of the students themselves, which implied the introduction of the concept of "self-registration" $[10,11]$. Any organized activity in the educational process was part of the assessment of students' achievements.

Centralization in government management that started in the 1930s determined the most significant milestones in the development of pedagogical ideas. The variety of approaches to the theoretical substantiation of assessment that existed at the previous stage was reduced to a number of basic points corresponding to the chosen political agenda. Out of the models created at the previous stage, the model of authoritarian control remained, the rest were sharply condemned. However, some of the ideas expressed among the criticized models were retained.

At the normatively defined stage (1932-1939), a principal model for assessing the quality of students' knowledge was created, based on the "teacher-student" interaction with the leading role of the teacher (Zaretsky, Shimbirev, et al.). It was the result of combining the significant points of the authoritarian control model and individual points of the control model based on the "teacher-student" interaction. At the same time, the leading role of the teacher in the assessment process was established [12]. The activity of the students was of significant importance in the educational process, but should not be carried out without the supervision of the teacher.

Let us determine the impact that the theoretical justification had on the development of the practice of Russian universities.

At the stage of regulatory and legal insecurity (1917-1921), the theoretical justification for assessment was not created in full, which made it impossible to speak of the existence of a model that could be applied in practice. As a result, any practical experience that makes it possible to exercise control and assessment was relevant.

The task of the earliest possible training of educated personnel set by the government at the experimental search stage (1922-1931), determined the need for the development of the didactics of higher education. Experimental verification was carried out for the main stated theoretical positions. Thus, to activate the educational process, a "laboratory-group system" was introduced, built according to a control model based on the "teacher-student" interaction [13]. On this basis, the rest of the components of the practical implementation of the assessment system were determined.

At the normatively defined stage (1932-1939), basic theoretical concepts were identified, on the basis of which normative documents were formed, as well as acceptable methods and forms of practical assessment [14]. The initially formed system of choice from 
a number of permissible possibilities gradually lost its flexibility and became more and more regulated.

The aspects that were not described in the normative and legal acts were intensely discussed in the pedagogical literature. Among them, setting up a system of criteria for justification of the ordered system of assessment [12] can be mentioned. Such a system allowed to easily assess the results of students' work, and was universal. At the same time, special features of academic subjects and students' peculiarities were not taken into account.

Summarizing the results obtained, we draw up the following table.

Table. Influence of theoretical ideas of teachers of the 1920-1930s on the practice of assessing the quality of students' knowledge.

\begin{tabular}{|l|l|l|l|}
\hline Stages & $\begin{array}{l}\text { Regulatory and } \\
\text { legal insecurity } \\
\text { Tendency }\end{array}$ & $\begin{array}{l}\text { Experimental search } \\
\mathbf{( 1 9 2 2 - 1 9 3 1 )}\end{array}$ & \multicolumn{1}{|c|}{$\begin{array}{l}\text { Normatively defined } \\
\text { (1932-1939) }\end{array}$} \\
\hline $\begin{array}{l}\text { The increasing role of } \\
\text { the teacher in assessing } \\
\text { the quality of students' } \\
\text { knowledge in the } \\
\text { process of } \\
\text { "teacher-student" } \\
\text { interaction }\end{array}$ & $\begin{array}{l}\text { Critical analysis } \\
\text { of } \\
\text { pre-revolutionary } \\
\text { didactics and } \\
\text { description of the } \\
\text { main directions } \\
\text { for further work }\end{array}$ & $\begin{array}{l}\text { Formation of three } \\
\text { basic assessment } \\
\text { models: authoritarian } \\
\text { control, control based } \\
\text { on teacher-student" the } \\
\text { "temteraction, } \\
\text { self-control }\end{array}$ & $\begin{array}{l}\text { Combining the models } \\
\text { created at the previous } \\
\text { stage into one: control } \\
\text { based on teacher-student" the } \\
\text { interaction with the } \\
\text { leading role of the } \\
\text { teacher }\end{array}$ \\
\hline
\end{tabular}

\section{Discussion}

The practical activity of universities in organizing the assessment of the quality of students' knowledge was primarily determined by those theoretical concepts that had developed among teachers at that time.

At the stage of normative and legal insecurity (1917-1921), pedagogical thought was mainly of a critical nature. The condemnation of the established pre-revolutionary practice revealed the main directions for further work.

Its result was the emergence of three basic models at the experimental search stage (1922-1931) (authoritarian control, control based on the "teacher-student" interaction and self-control), tested in practice. The main attention was paid to the control model based on the "teacher-student" interaction, since it combined not only the intense activity of the teacher, but also the students themselves. The other two models were implemented to a lesser extent. The former was closely related to the traditional assessment system and did not need special testing, and the latter did not have significant registered results that would allow judging the achievements of students. The problem of identifying individual achievements of students, described in the period under review (1917-1939), is still relevant today. Zemlyanskaya addresses this issue, noting that tracking individual results of students can be performed using formative assessment [15].

The tightening of the political regime led to the formation of a unified theoretical model at the regulatory legal stage (1932-1939) that combined the results of the main theoretical achievements of the previous stage. The implementation of the control practice was built in accordance with the specified model. While initially a fairly wide number of different aspects were given to teachers for their own solution, at the end of the period under consideration, a single basic system for assessing the quality of students' knowledge was formed, mandatory for common use. 


\section{Conclusion}

The result of the study is basic models that describe the theoretical ideas of teachers of the 1920-1930s: authoritarian, control based on the "teacher-student" interaction, self-control and control based on the "teacher-student" interaction with the leading role of the teacher. Practical implementation of the described theoretical concepts in the work of universities from 1917 to 1939 made it possible to reveal the tendency of increasing the role of the teacher in assessing the quality of students' knowledge in the process of "teacher-student" interaction.

A further direction of research development can be the study of the assessment system at the regulatory, legal and instructive-methodological levels.

\section{References}

1. I. Gil-Jaurena, S. Kucina, Int. J. Edu. Tech. Higher Edu. 13(17), 2-3 (2016). https://doi.org/10.1186/s41239-016-0016-z

2. E. Alyahyan, D. Düştegör, Int. J. Edu. Tech. Higher Edu. 17(3), 3-4 (2020). https://doi.org/10.1186/s41239-020-0177-7

3. N.V. Leontyeva, Razvitie sistemy otsenki kachestva znanii studentov v rossiiskoi vysshei shkole v 20-30-e gg. XX v. [Development of a System for Assessing the Quality of Students' Knowledge in Russian Higher Education in the 1920-1930s], PhD Thesis in Pedagogy (Glazov, 2011).

4. M.V. Boguslavsky, et al., Prob. Contemp. Edu. 2, 110 (2019)

5. S.T. Shatsky, Na puti k trudovoi shkole [On the Way to Labor School], in Selected pedagogical writings: in 2 v. (Pedagogy, Moscow, 1980)

6. V.A. Kilchevsky, Obshchestvenno-kooperativnaya shkola [Public Cooperative School] (Yaroslavl Publishers of the Credit Union of Cooperators, Yaroslavl, 1919)

7. V.B. Pomelov, Tendentsii razvitiya rossiiskogo obrazovaniya pervoi poloviny XX v. [Trends in the Development of Russian Education in the First Half of the $20^{\text {th }}$ Century] (Vyatka State University, Kirov, 2020)

8. P.P. Blonsky, On the Way to New Sch. 7-8, 40-51 (1926)

9. R.M. Mickelson, Uchet kak sostavnaya chast pedagogicheskogo protsessa [Accounting as an Integral Part of the Pedagogical Process], in Exam and Psyche. Experimental research: the work of the psychological laboratory of the Krupskaya Academy of Communist Education (State Publishers, Moscow, 1929)

10. K.N. Wentzel, On the Way to New Sch. 4, 69 (1923)

11. A.P. Pinkevich, Pedagogika. T. 2. Trudovaya shkola [Pedagogy. V. 2. Labor School] (Education Worker, Moscow, 1925)

12. M.I. Zaretsky, Soviet Pedag. 4, 28-38 (1938)

13. V.T. Kasatkin, Pub. Edu. 4, 119, (1925)

14. I.K. Rybakov, For Indust. Pers. 8-9, 30 (1933)

15. E.N. Zemlyanskaya, Contemp. Foreign Psy. 5(3), 52 (2016). https://doi.org/10.17759/jmfp.2015050306 